\title{
The Relationship Between Vasoactive-Inotropic Score and Mortality in Adult Patients with Traumatic Brain Injury
}

\author{
Iskender KARA ${ }^{1}$, Mehmet SARGIN², Yesim Serife BAYRAKTAR ${ }^{1}$, Mert SAHINOGLU³ , Gurban ILDAROV², \\ Ipek DUMAN ${ }^{4}$, Jale Bengi CELIK ${ }^{1}$, Hakan KARABAGLI ${ }^{3}$

\begin{abstract}
'Selcuk University, Faculty of Medicine, Department of Anesthesiology and Reanimation, Division of Critical Care Medicine, Konya, Turkey ${ }^{2}$ Selcuk University, Faculty of Medicine, Department of Anesthesiology and Reanimation, Konya, Turkey

${ }^{3}$ Selcuk University, Faculty of Medicine, Department of Neurosurgery, Konya, Turkey

${ }^{4}$ Necmettin Erbakan University, Meram Faculty of Medicine, Department of Medical Pharmacology, Konya, Turkey
\end{abstract}

Corresponding author: Iskender KARA driskenderkara@gmail.com

\section{ABSTRACT}

AIM: To assess the feasibility of the vasoactive-inotropic score (VIS) in determining the amount of vasoactive support and its relationship with the mortality rate and characteristics of the patients with traumatic brain injury (TBI).

MATERIAL and METHODS: This study was conducted with a retrospective design involving the years 2013-2018 in a university hospital which provides tertiary intensive care service. A total of 102 patients who were admitted in the ICU with the diagnosis of severe TBI, and also were followed by neurosurgery service and who received vasoactive and inotropic support were analyzed concerning VIS value.

RESULTS: The median age of the patients was 34 years, and $69.6 \%$ of the patients were male. Mortality rate was $43.1 \%$. In the group with mean VIS $\geq 10$, the admission duration in the ICU and hospital were shorter $(p<0.0001)$ whereas mortality rates were higher $(81.1 \%$ vs $21.5 \%$ and $p<0.0001)$. Besides, the number of patients with a VIS score of $\geq 10, \geq 15$ and $\geq 20$ were higher in the group of patients who died $(\mathrm{p}<0.0001)$. The results of the multivariate analysis such as VIS $\geq 10$ were significant.

CONCLUSION: We can conclude that VIS, which is used to determine the amount of vasoactive and inotropic medicines during cardiac surgery and in sepsis patients, may be useful in predicting mortality in TBI patients.

KEYWORDS: Traumatic brain injury, Vasoactive-inotropic score, Mortality, Intensive care unit

\section{INTRODUCTION}

$\mathrm{I}$ $\mathrm{t}$ is expected that approximately eight million people would die due to injury in the year 2020 worldwide (10). Head trauma and severe traumatic brain injury (TBI) which has an important place among all the trauma patients, affect annually approximately 5.48 million people worldwide. TBI, also termed as "the silent epidemic" is the traumatic injury which leads to the highest mortality and morbidity. TBI as one of the preventable death causes also has an essential place among mortality and disability reasons in the patient population aged below 40 years old $(3,11)$.
The patients with TBI are usually managed in the Intensive Care Unit (ICU). The sensitive balance between ensuring adequate cerebral perfusion pressure and fluid overload is very crucial. At this stage, the administration of the vasopressor and inotropic drugs orientates the treatment process. It is controversial how fluid replacement and administration of the vasoactive medications should be managed in case of hypotension in the patients with TBI (10). Vasoactive-inotropic score (VIS) which is evaluated mostly in cardiac surgery patients in recent years is based on the calculation of the amounts of the administered vasoactive drugs. This calculated score can be used in predicting mortality rates in patients with TBI followed in the $\operatorname{ICU}(5,6,13,22)$.
Iskender KARA Mehmet SARGIN

(D) : $0000-0002-2753-3670$

(D) : 0000-0002-6574-273X

Yesim Serife BAYRAKTAR (D) : 0000-0001-5156-7064
Mert SAHINOGLU (1) : 0000-0003-0633-8304

Gurban ILDAROV (D) : 0000-0002-9014-1485 Ipek DUMAN
Jale Bengi CELIK (1) : 0000-0003-2167-9967 Hakan KARABAGLI (D) : 0000-0002-1184-3965 
We aimed to assess the feasibility of VIS in predicting the outcome of TBI patients receiving vasoactive supplementation in the early term who are managed in the ICU.

\section{MATERIALS and METHOD}

The present study was approved by The Ethics Committee of Selcuk University Medical Faculty (Number: 2018/314). Archive and data processing system of the hospital was used. In this study, the 102 patients who were admitted in the ICU with diagnosis of TBI, and also follow up by neurosurgery and who were receiving vasoactive and inotropic support were evaluated for their VIS value. The files of the patients with head injury who were admitted in the anesthesiology and reanimation ICU between January 2013 to July 2018 were analyzed retrospectively. Data such as demographic characteristics of the patients, type of head injury, medical and surgical interventions, duration of hospital and ICU stay and outcomes were recorded. Mean VIS values of the patients in the first 48 hours were calculated and the patients were divided into two groups as subjects with a VIS of $<10$ and $\geq 10$. The parameters associated with VIS were analyzed. The patients were divided into two groups as dead and survivors and were statistically analyzed concerning general characteristics and VIS.

Patients admitted to the ICU with a history of head injury, older than 18 years of age who received vasopressor or inotropic support within the first 48 hours of admission were included in the study. Patients with uncontrolled hemorrhagic shock, coagulopathy, and spinal cord injury were excluded.

\section{Calculation of VIS}

The doses of adrenaline, noradrenaline, dopamine, dobutamine, milrinone, and vasopressin of the patients within the first $0^{\text {th }}, 6^{\text {th }}, 12^{\text {th }}, 24^{\text {th }}$ and $48^{\text {th }}$ hours beginning from admission to the ICU were recorded. Overall VIS values were obtained by using the mean value of each agent. The following Formula was used to calculate the VIS value (Figure 1) $(5,22)$.

\section{Statistical Analysis}

Data were statistically analyzed using SPSS Version 22.0 (Statistical Package for the Social Sciences Inc., Chicago, IL, USA). Data were tested for normality with KolmogorovSmirnov (with Lilliefors correction) and Shapiro-Wilk tests. Descriptive statistics were performed in all the patient groups; numerical data were expressed as median (quarter intervals) while categorical data were given as percentages. Patients were classified according to mean VIS (VIS $<10$ or $V I S \geq 10$ ), and ICU outcomes (dead or survive). Patient features were compared using Chi-Square or Fisher's Exact Test for categorical variables and Mann-Whitney $U$ Test for numerical variables. $p<0.05$ value was accepted as statistically significant. To identify any independent risk factor associated with mortality, among the significant parameters of univariate analysis, the ones which were not associated with each other were entered into the multivariate linear regression analysis. $\mathrm{ROC}$ analysis was performed.

\section{RESULTS}

\section{General Characteristics of the TBI Patients}

During the study period, a total of 194 patients with traumatic brain injury were admitted and treated in the ICU. Data of 102 patients with TBI which met the inclusion criteria were analyzed. The median age of the patients were 34 (range: 2351) years, and $69.6 \%(n=71)$ of the patients were male. Median Acute Physiology and Chronic Health Evaluation II (APACHE II) and Glasgow Coma Scale (GCS) values were 20 (18-24) and $5(3-8)$, respectively. The rate of patients on mechanical ventilation support was $86.3 \%(n=88)$. The incidence of isolated head injury was $20.6 \%$ ( $n=21)$. Of the patients; $22.5 \%$ $(n=23)$ underwent neurosurgical procedures whereas $22.5 \%$ $(n=23)$ were operated for non-cerebral events. The median duration of ICU and hospital stay were $6(2.75-18)$ and 10 (323) days, respectively. The mortality rate of the patients was 43.1\% ( $n=44)$ (Table I).

\section{Head Trauma and Diagnoses}

All head trauma patients were evaluated in the emergency department by the physicians of the neurosurgery service. TBI patients we transferred to the anesthesia and reanimation ICU for postoperative management after neurosurgical interventions. The rates of TBI between in-vehicle traffic accidents and fall injuries were $38.2 \%(n=39)$ and $24.5 \%$ $(n=25)$, respectively. On the other hand, the rates of motorcycle accidents and non-vehicle traffic accidents were 18.6\% $(n=19)$ and $13.7 \%(n=14)$, respectively. The incidence of TBI due to other reasons such as occupational accidents, explosions, and gunshot injuries was $4.9 \%(n=5)$. Overall the admission rate of the patients after traffic accidents was $70.6 \%(n=72)$.

The most common diagnosis for admission to the ICU was subarachnoid hemorrhage and skull fractures (i.e.: compression fracture) (53.9\% and $44.1 \%$, respectively) (Table I).

\section{Patients and Vasopressor Medications}

The number of patients who received noradrenaline, adrenaline, dopamine, and dobutamine and the median doses were $5(2-10) \mu \mathrm{g} / \mathrm{kg} / \mathrm{min}$ in 99 patients, $5(4.25-7) \mu \mathrm{g} / \mathrm{kg} / \mathrm{min}$ in 20 patients, $6.5(3-10.25) \mu \mathrm{g} / \mathrm{kg} / \mathrm{min}$ in 34 patients and 15 $(12.5-15) \mu \mathrm{g} / \mathrm{kg} / \mathrm{min}$ in 5 patients, respectively. No patient received vasopressin or milrinone (Table I).

\section{The Patient Characteristics in Terms of Mean VIS}

The patients in the group with mean VIS $\geq 10$ were older and had lower GCS values ( $p=0.005$ and $p=0.013$ respectively).

Vasoactive-Inotropic Score = dopamine dose $(\mu \mathrm{g} / \mathrm{kg} / \mathrm{min})+$ dobutamine dose $(\mu \mathrm{g} / \mathrm{kg} / \mathrm{min})+100$ xadrenaline dose $(\mu \mathrm{g} /$ $\mathrm{kg} / \mathrm{min})+100 \times$ noradrenaline dose $(\mu \mathrm{g} / \mathrm{kg} / \mathrm{min})+10 \times$ milrinone dose $(\mu \mathrm{g} / \mathrm{kg} / \mathrm{min})+10.000 \times$ vasopressin dose $(U / \mathrm{kg} / \mathrm{min})$

Figure 1: Vasoactive-inotropic score (VIS) formula. 
Table I: General Characteristics of Traumatic Brain Injury Patients

\begin{tabular}{|c|c|}
\hline Variable & $\begin{array}{c}\text { Total Patients } \\
(\mathrm{n}=102) \\
\text { Median (IQR) or } \\
n(\%)\end{array}$ \\
\hline Age (years) & $34(23.75-51)$ \\
\hline Gender (male) & $71(69.6 \%)$ \\
\hline APACHE II score & $20(18-24)$ \\
\hline GCS score & $5(3-8)$ \\
\hline Mechanical ventilation & $88(86.3 \%)$ \\
\hline Isolated head injury & $21(20.6 \%)$ \\
\hline Neurosurgical intervention & $23(22.5 \%)$ \\
\hline Other surgical interventions & $23(22.5 \%)$ \\
\hline Hemoglobin (gr/dl) & $10.5(9.7-12.4)$ \\
\hline Red Blood Cell replacement & $49(48 \%)$ \\
\hline Number of Red Blood Cell (Unit) & $2(2-3)$ \\
\hline Fresh Frozen Plasma replacement & $35(34.7 \%)$ \\
\hline Number of Fresh Frozen Plasma (Unit) & $1(1-2)$ \\
\hline Volume balance (ml/day) & $544(254-850)$ \\
\hline Length of ICU stay (day) & $6(2.75-18)$ \\
\hline Length of hospital stay (day) & $10(3-23)$ \\
\hline Outcome (Death) & $44(43.1 \%)$ \\
\hline Type of trauma & n (\%) \\
\hline Traffic accident (inside the vehicle) & $39(38.2)$ \\
\hline $\begin{array}{l}\text { Traffic accident } \\
\text { (outside the vehicle) }\end{array}$ & $14(13.7)$ \\
\hline Fall injury & $25(24.5)$ \\
\hline Motorcycle accident & $19(18.6)$ \\
\hline $\begin{array}{l}\text { Others (Explosion, work accident, } \\
\text { penetrating head injury) }\end{array}$ & $5(4.9)$ \\
\hline Diagnosis of hospitalization & n (\%) \\
\hline Cerebral edema & $30(29.4)$ \\
\hline Subdural hemorrhage & $25(24.5)$ \\
\hline Epidural hemorrhage & $17(16.7)$ \\
\hline Intracerebral hemorrhage & $12(11.8)$ \\
\hline Subarachnoid hemorrhage & $55(53.9)$ \\
\hline Pneumocephalus & $4(3.9)$ \\
\hline Cerebral contusion & $12(11.8)$ \\
\hline Diffuse axonal injury & $5(4.9)$ \\
\hline Skull fractures & $45(44.1)$ \\
\hline Skull base fractures & 37 (36.3) \\
\hline Others & $2(2)$ \\
\hline Supportive treatment & Median (IQR) \\
\hline Noradrenaline ( $\mu \mathrm{g} / \mathrm{kg} / \mathrm{min}),(\mathrm{n}=99)$ & $5(2-10)$ \\
\hline Adrenalin ( $\mu \mathrm{g} / \mathrm{kg} / \mathrm{min}),(n=20)$ & $5(4.25-7)$ \\
\hline Dopamine $(\mu \mathrm{g} / \mathrm{kg} / \mathrm{min}),(\mathrm{n}=34)$ & $6.5(3-10.25)$ \\
\hline Dobutamine ( $\mu \mathrm{g} / \mathrm{kg} / \mathrm{min}),(\mathrm{n}=5)$ & $15(12.5-15)$ \\
\hline
\end{tabular}

APACHE II: Median acute physiology and chronic health evaluation II, GCS: Glasgow coma scale, ICU: Intensive care unit.
The duration of stay in the ICU and hospital were shorter in the group with a mean VIS of $\geq 10(p<0.0001)$. A significantly higher mortality rate was found in this group $(81.1 \%$ vs $21.5 \%$ and $p<0.0001)$. In the group with a mean VIS of $\geq 10$ demonstrated a higher rate of diagnosed subarachnoid hemorrhage and a lower rate of skull fractures $(67.6 \%$ vs. $46.2 \% ; p=0.042$ and $29.7 \%$ vs. $52.3 \%$; $p=0.038$ respectively) (Table II).

\section{The Patient Characteristics in Terms of Mortality}

In the group of patients who died, GCS value (3 vs. 6; $\mathrm{p}<0.0001)$ was lower, whereas higher mechanical ventilation rates $(100 \%$ vs $75.9 \%$; $p<0.0001)$ and $\mathrm{APACHE}$ II values were encountered ( 22.5 vs. $20 ; p=0.027$ ). The rate of the non-cerebral surgeries was found higher in the survivor group (31\% vs. $11.4 \% ; p=0.030)$. The group of patients who died had a shorter duration of stay both in the ICU and the hospital (2.5 vs 14 and 2.5 vs 18.5; $p<0.0001$, respectively). In this group, the number of patients with a VIS of $\geq 10, \geq 15$ and $\geq 20$ were significantly higher $(p<0.0001)$. The group also had higher rates of subarachnoid hemorrhage $(77.3 \%$ vs $36.2 \%$; $p<0.0001$ ) whereas incidence of epidural hemorrhage and skull fractures were lower $(6.8 \%$ vs $24.1 \%$; $p=0.030$ and $29.5 \%$ vs $55.2 \%$; $p=0.015$ ) (Table III).

The parameters with significant results according to univariate analysis were evaluated with multivariate analysis. The parameters such as VIS $\geq 10$ [OR 157.2, 95\% Cl 4.3-5709.8, $\mathrm{p}=0.006$ ], duration of ICU stay [OR $2.45,95 \% \mathrm{Cl} 1.37-4.40$, $\mathrm{p}=0.003$ ], duration of hospital stay [OR $0.33,95 \% \mathrm{Cl} 0.17-$ $0.63, p=0.001$ ], non-cerebral surgeries [OR $0.31,95 \% \mathrm{Cl}$ $0.001-0.86, p=0.041]$ and presence of skull fractures [OR $0.041,95 \% \mathrm{Cl} 0.003-0.631, \mathrm{p}=0.022]$ were determined as independent risk factors (Table III).

\section{The Correlation Between Mean Cutoff VIS value and Mortality}

The cut-off value of mean VIS values according to the ROC analysis performed to predict mortality rate was found as 7.5 (Figure 2). The sensitivity and specificity values for the VIS $=7.5$ cut-off value were $72.7 \%$ and $74.1 \%$, respectively. Positive predictive value, negative predictive value and overall consistency values were found as $68.1 \%, 78.2 \%$ and $73.5 \%$, respectively [AUC 0,863 and 95\% $\mathrm{Cl} 0.794-0.931, \mathrm{p}<0.0001$ ] (Table IV).

\section{DISCUSSION}

To the best of our knowledge, this is the first study in the literature to assess the patients with TBI in respect of VIS. According to the outcomes of our patients, a VIS value of $\geq 10$ was found to be associated with increased mortality. Additionally, mortality rates progressively increased with the increase in VIS, and it was consequently noticed that no patient with a VIS of $\geq 20$ survived.

TBI is one of the principal causes of mortality in the age group below 40 years old (11). Mean age was 34 years while male patients made $69.6 \%$ of the study population in our study. The ages and gender ratios of the patients with severe TBI in a retrospective study were compliant with the results of our 
Table II: The Patient Characteristics in Terms of Mean VIS

\begin{tabular}{|c|c|c|c|c|}
\hline \multirow[b]{3}{*}{ Variable } & \multicolumn{3}{|c|}{ Univariate Analysis } & \multirow[t]{2}{*}{ LR } \\
\hline & \multicolumn{2}{|c|}{ Vasoactive-Inotropic Score } & \multirow[t]{2}{*}{$\mathbf{p}$} & \\
\hline & $\begin{array}{c}\text { Mean VIS <10 } \\
n=65(63.7 \%) \\
\text { Median (IQR) or } n(\%)\end{array}$ & $\begin{array}{c}\text { Mean VIS } \geq 10 \\
n=37(36.3 \%) \\
\text { Median (IQR) or } n(\%)\end{array}$ & & \\
\hline Age (years) ${ }^{a}$ & $31(23-44)$ & $40(27.5-63)$ & 0.005 & NS \\
\hline Gender (male) & $45(69.2 \%)$ & $26(70.3 \%)$ & 1.000 & \\
\hline APACHE II score & $20(17.5-22)$ & $22(18-26)$ & 0.052 & \\
\hline GCS score $^{a}$ & $6(3-8)$ & $3(3-7.5)$ & 0.013 & NS \\
\hline Mechanical ventilation & $53(81.5 \%)$ & $35(94.6 \%)$ & 0.078 & \\
\hline Isolated head injury & $16(24.6 \%)$ & $5(13.5 \%)$ & 0.212 & \\
\hline Neurosurgical intervention & $18(27.7 \%)$ & $5(13.5 \%)$ & 0.139 & \\
\hline Other surgical interventions & $15(23.1 \%)$ & $8(21.6 \%)$ & 1.000 & \\
\hline Hemoglobin (gr/dl) & $10.5(9.7-12.5)$ & $10.2(9.7-12)$ & 0.524 & \\
\hline Red Blood Cell replacement & $29(44.6 \%)$ & $20(54.1 \%)$ & 0.413 & \\
\hline Number of Red Blood Cell (Unit) & $2(2-3)$ & $2(2-3)$ & 0.920 & \\
\hline Fresh Frozen Plasma replacement & $19(29.7 \%)$ & $16(43.2 \%)$ & 0.196 & \\
\hline Number of Fresh Frozen Plasma(Unit) ${ }^{a}$ & $1(1-2)$ & $2(1-5)$ & 0.022 & NS \\
\hline Volume balance (ml/day) & $549(258-850)$ & $510(250-750)$ & 0.374 & \\
\hline Length of ICU stay (day) ${ }^{a}$ & $9(4-21.5)$ & $2(1-8)$ & $<0.0001$ & NS \\
\hline Length of hospital stay (day) ${ }^{a}$ & $12(6-26)$ & $2(1-16)$ & $<0.0001$ & NS \\
\hline Outcome (death) ${ }^{\mathrm{a}}$ & $14(21.5 \%)$ & $30(81.1 \%)$ & $<0.0001$ & NS \\
\hline Type of trauma & n (\%) & n (\%) & & \\
\hline Traffic accident (inside the vehicle) & $22(33.8)$ & $17(45.9)$ & 0.290 & \\
\hline Traffic accident (outside the vehicle) & $10(15.4)$ & $4(10.8)$ & 0.766 & \\
\hline Fall injury & $17(26.2)$ & $8(21.6)$ & 0.642 & \\
\hline Motorcycle accident & $13(20)$ & $6(16.2)$ & 0.920 & \\
\hline Others & $3(4.6)$ & $2(5.4)$ & 1.000 & \\
\hline Diagnosis of hospitalization & n (\%) & n (\%) & & \\
\hline Cerebral edema & $14(21.6)$ & $16(43.2)$ & 0.155 & \\
\hline Subdural hemorrhage & $18(27.7)$ & 7 (18.9) & 0.351 & \\
\hline Epidural hemorrhage & $14(21.5)$ & $3(8.1)$ & 0.101 & \\
\hline Intracerebral hemorrhage & $10(15.4)$ & $2(5.4)$ & 0.203 & \\
\hline Subarachnoid hemorrhage ${ }^{a}$ & $30(46.2)$ & $25(67.6)$ & 0.042 & NS \\
\hline Pneumocephalus & $2(3.1)$ & $2(5.4)$ & 0.620 & \\
\hline Cerebral contusion & $8(12.3)$ & $4(10.8)$ & 1.000 & \\
\hline Diffuse axonal injury & $5(7.7)$ & $0(0)$ & 0.156 & \\
\hline Skull fractures ${ }^{a}$ & $34(52.3)$ & $11(29.7)$ & 0.038 & NS \\
\hline Skull base fractures & $22(33.8)$ & $15(40.5)$ & 0.527 & \\
\hline Others & $2(3.1)$ & $0(0)$ & 0.533 & \\
\hline
\end{tabular}

The parameters in bold indicate the significant ones in univariate analysis. VIS: Vasoactive-inotropic score, LR: Logistic regression, NS: Nonsignificant, APACHE II: Median acute physiology and chronic health evaluation II, GCS: Glasgow coma scale, ICU: Intensive care unit. ${ }^{a}$ Marked parameters which were significant in univariate analysis and not associated with each other were included in the multivariate analysis 
Table III: The Patient Characteristics in Terms of Mortality

\begin{tabular}{|c|c|c|c|c|c|}
\hline \multirow[b]{3}{*}{ Variable } & \multicolumn{3}{|c|}{ Univariate Analysis } & \multicolumn{2}{|c|}{ Multivariate analysis } \\
\hline & \multicolumn{2}{|c|}{ Vasoactive-Inotropic Score } & \multirow[t]{2}{*}{$\mathbf{p}$} & \multirow[t]{2}{*}{ OR } & \multirow[t]{2}{*}{$\mathbf{p}$} \\
\hline & $\begin{array}{c}\text { Survive group } \\
\mathrm{n}=58(56.9 \%) \\
\text { Median (IQR) or } \\
\mathrm{n}(\%)\end{array}$ & $\begin{array}{c}\text { Death group } \\
\mathrm{n}=44(43.1 \%) \\
\text { Median (IQR) or } \\
\mathrm{n}(\%)\end{array}$ & & & \\
\hline Age (years) & $34(23-49)$ & $35(24-55.75)$ & 0.763 & & \\
\hline APACHE II score ${ }^{a}$ & $20(18-21.25)$ & $22.5(17.25-26)$ & 0.027 & & \\
\hline GCS score $^{a}$ & $6(4-12)$ & $3(3-5)$ & $<0.0001$ & & \\
\hline Mechanical ventilation ${ }^{a}$ & $44(75.9 \%)$ & $44(100 \%)$ & $<0.0001$ & & \\
\hline Isolated head injury & $14(24.1 \%)$ & $7(15.9 \%)$ & 0.336 & & \\
\hline Red Blood Cell replacement & $27(46.6 \%)$ & $22(50 \%)$ & 0.842 & & \\
\hline Number of Red Blood Cell (Unit) & $2(2-3)$ & $2(2-3)$ & 0.750 & & \\
\hline Fresh Frozen Plasma replacement & $20(34.5 \%)$ & $15(34.9 \%)$ & 1.000 & & \\
\hline Number of Fresh Frozen Plasma (Unit) & $1(1-2)$ & $2(1-5)$ & 0.167 & & \\
\hline Volume balance (ml/day) & $544(263-850)$ & $450(250-850)$ & 0.214 & & \\
\hline Length of ICU stay (day) & $14(5-29)$ & $2.5(1-5.75)$ & $<0.0001$ & $2.45(1.37-4.40)$ & 0.003 \\
\hline Length of hospital stay (day) & $18.5(9.75-34)$ & $2.5(1-5.75)$ & $<0.0001$ & $0.33(0.17-0.63)$ & 0.001 \\
\hline Mean VIS ${ }^{a}$ & $3(1-8)$ & $15.5(6.25-31.75)$ & $<0.0001$ & & \\
\hline Mean VIS $\geq 10$ & $7(12.1 \%)$ & $30(68.2 \%)$ & $<0.0001$ & $157.2(4.3-5709.8)$ & 0.006 \\
\hline Motorcycle accident & $10(17.2)$ & $9(20.4)$ & 0.443 & & \\
\hline Others & $3(5.2)$ & $2(4.5)$ & 0.632 & & \\
\hline Diagnosis of hospitalization & $\mathrm{n}(\%)$ & n (\%) & & & \\
\hline Cerebral edema & $16(27.6)$ & $14(31.8)$ & 0.785 & & \\
\hline Subdural hemorrhage & $15(25.9)$ & $10(22.7)$ & 0.818 & & \\
\hline Epidural hemorrhage $^{a}$ & $14(24.1)$ & $3(6.8)$ & 0.030 & & \\
\hline Intracerebral hemorrhage & $6(10.3)$ & $6(13.6)$ & 0.758 & & \\
\hline Subarachnoid hemorrhage ${ }^{a}$ & $21(36.2)$ & $34(77.3)$ & $<0.0001$ & & \\
\hline Pneumocephalus & $1(1.7)$ & $3(6.8)$ & 0.189 & & \\
\hline Cerebral contusion & $8(13.8)$ & $4(9.1)$ & 0.547 & & \\
\hline Diffuse axonal injury & $3(5.2)$ & $2(4.5)$ & 0.885 & & \\
\hline Skull fractures & $32(55.2)$ & $13(29.5)$ & 0.015 & $0.041(0.003-0.63)$ & 0.022 \\
\hline Skull base fractures & $20(34.5)$ & $17(38.6)$ & 0.683 & & \\
\hline Others & $1(1.7)$ & $1(2.3)$ & 0.843 & & \\
\hline
\end{tabular}

The parameters in bold indicates the significant ones in univariate and multivariate analysis. VIS: Vasoactive-Inotropic Score, APACHE II: Median Acute Physiology and Chronic Health Evaluation II, GCS: Glasgow Coma Scale, ICU: Intensive Care Unit. ${ }^{a}$ Marked parameters which were significant in univariate analysis and not associated with each other were included in the multivariate analysis. 
study where $83.2 \%$ of the patients were admitted due to traffic accidents (17). According to literature data, the most common cause of $\mathrm{TBI}$ is traffic accidents in the low and moderateincome countries while the frequency of fall injuries increases depending on increased population of elderly subjects $(3,11)$. In our study, $70.6 \%$ of the TBI cases occurred due to traffic accidents while fall injuries were the second most common cause. These patients were admitted most frequently associated subarachnoid hemorrhage.

The TBI patients are usually referred to the intensive care unit following first medical intervention after injury. In the ICU, secondary brain injury which may develop due to increased intracranial pressure is avoided while the most appropriate intervention is performed to recover the initial damage. The vasopressor drugs in presence of risk for cerebral edema

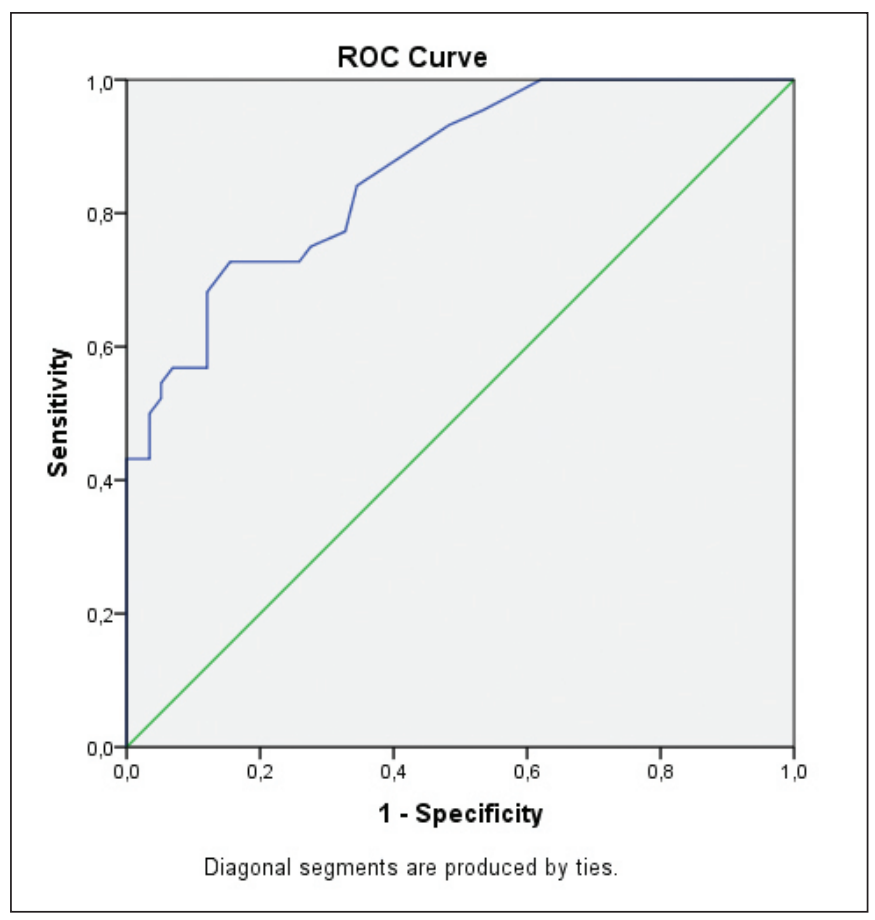

Figure 2: Receiver Operating Characteristic (ROC) curve for mean Vasoactive-inotropic score (VIS). which may develop in the clinical course of refractory shock or transfusion of fluids and blood components are added to the fluid replacements. Because hypotension is commonly observed after TBI and it may affect survival $(9,12,20)$. Mortality rate was found at $43.1 \%$ in this patient group in the present study.

Various scoring systems are used in prediction of mortality rates in the TBI patients who are admitted to the ICU (15). In some cases, many laboratory techniques may be needed to calculate these scores. New scoring systems to achieve this goal are frequently introduced to clinical practice (21). Use of VIS is distinct which has been used in a limited number of studies in recent years. These studies have been carried out in especially postoperative pediatric cardiac patients $(5,6,13)$. There are also studies on VIS in pediatric sepsis patients $(8,14)$. Recently, VIS was used in the adult cardiac surgery patients (22). Our study has assessed the use of VIS in the TBI patients who were managed in a tertiary intensive care unit which received vasoactive drug support.

Similarly, with the study which evaluated VIS in 71 pediatric patients in the clinical picture of refractory septic shock, our mortality rate was found to be $100 \%$ in patients with a VIS of $>20$ (8). Another study has evaluated VIS as a prognostic scoring system in the adolescents (10-18 years) who underwent cardiac surgery. It was stated that VIS correlated with the duration of hospital stay and duration to extubation. As a result, VIS has been recommended as an easy, relevant and accurate prognostic indicator (7). An editorial letter has evaluated the data of 390 patients who received preoperative vasopressor supplementation out of 711 patients who underwent cardiac transplantation for heart failure. The complication and mortality rates after cardiac transplantation were found significantly higher in the patients with preoperative VIS $>20$ (1). Another study has evaluated VIS in the cardiogenic shock patients. The 493 patients were divided into five groups based on VIS values (VIS: 1 to 10,11 to 20,21 to 38,39 to 85 , and > 85). Mortality rates were discovered as $8.2 \%, 14.1 \%, 21.1 \%$, $32.0 \%$, and $65.7 \%(p<0.001)$, respectively. As a consequence, high VIS values within the first 48 hours in the clinical course of cardiogenic shock was found to be associated with a nincreased mortality rate. The increased VIS values were also

Table IV: Receiver Operating Characteristic Analysis for the Prediction of Mortality. Cut-Off for Survive Group Versus Death Group Mean VIS Based on ROC Analysis

\begin{tabular}{lcccccc}
\hline & \multicolumn{2}{c}{ AUC } & p & $\begin{array}{c}\text { Asymptotic } 95 \% \text { confidence intervals } \\
\text { lower bound-upper bound }\end{array}$ & Cut-off value \\
\hline Mean VIS & \multicolumn{7}{c}{0.863} & $<\mathbf{0 . 0 0 0 1}$ & $0.794-0.931$ & $\geq 7.5$ \\
\hline \multicolumn{7}{c}{ Outcome: death } \\
\hline \multirow{8}{*}{ Mean VIS $=7.5$} & Yes & No & Total & Sensitivity & $32 / 44=\% 72.7$ \\
\hline & No & 12 & 15 & 47 & Specificity & $43 / 58=\% 74.1$ \\
\hline & Total & 44 & 58 & 102 & Predictive value of negative test & $43 / 55=\% 78.2$ \\
\hline
\end{tabular}

ROC: Receiver operating characteristic, AUC: Area under the curve, VIS: Vasoactive-inotropic score. 
associated with cardiac arrest, reduced $\mathrm{pH}, \mathrm{APACHE}$ II Score, and increased lactic acidosis (16). In the present study, VIS values were higher in the patients diagnosed with subarachnoid hemorrhage who had significantly higher mortality rates. Similarly, low GCS value was associated with both increased mortality and high VIS values.

Another study analyzed VIS in sepsis patients aged between 2 months and 18 years. The admission duration in the ICU, rates of mechanical ventilation and mortality were found to be associated with VIS (14). The predictive strength of VIS for mortality and morbidity was assessed in 129 patients who underwent cardiopulmonary by-pass surgery. It reported that a high level of VIS value was effective in predicting mortality and morbidity. In addition, the patient group with high VIS level received longer duration of mechanical ventilation support and duration of stay in the ICU (22). Contrarily, the patients with higher VIS values had a significantly shorter duration of stay both in the ICU and the hospital in our study. In our study, shorter duration of stay was due to increased mortality accompanied with increased VIS values within the first 48 hours in the ICU.

There is a long-standing debate on the fact how hemodynamic balance will be achieved and how fluid treatment and vasopressors will be administered $(10,12)$. There are a few studies which compared the efficacy of the vasopressors commonly used in the treatment of TBI and the outcomes of these studies are controversial (19). Besides, there is only a limited number of studies which investigated the use of vasopressors during the early stage of the resuscitation period in the traumatic brain injury patients with very high mortality rate (9). In the present study, the early stages of the TBI patients involving the first 48 hours in the ICU were analyzed. It was observed that use of vasopressors during this period might be ineffective when administered over optimal levels. According to the outcomes of our study, VIS may be preferred conveniently in predicting the adequate level of this support. As a matter of fact, a study carried out in the cardiac intensive care units has suggested that the patients who have received three or more vasoactive drugs usually did not survive. It has been reported that addition of third and fourth vasoactive drug without percutaneous intervention or revascularization surgery which can reverse the shock in these patients is ineffective (18). The available evidence does not support preferring any vasopressor to another (2). In this sense, this score calculated by total values of the drugs used in VIS presents an overall value independent from the fact which vasopressor was used. Although, some authors recommended the addition of drugs such as levosimendan to the VIS score, the calculations made by the addition of the drugs which are more commonly used drugs in clinical practice can be more effective (4). Accordingly, we have preferred the more commonly used agents in the treatment of TBI patients such as noradrenaline, dopamine, adrenaline, and dobutamine. Vasopressin and milrinone were not used in our study since the other studies on VIS involving administration of these drugs were carried out with the cardiac or sepsis patients. Besides, the cut-off value of VIS was found 7.5 in prediction of mortality according to the ROC analysis.

\section{Limitations}

The present study has several limitations. First of all, we had no previously determined criteria on the facts such as combinations of the vasoactive drugs, dose adjustments and targeted blood pressure since our study was performed retrospectively. A second limitation was the relatively small number of patients since our study was a single-center study that were carried out in a single ICU. Finally, another limitation of our study was the fact that milrinone and vasopressin were not used in the treatment of hypotension in the analyzed patient group and that VIS value was calculated without the addition of these drugs.

\section{- CONCLUSION}

Profit and loss should be taken into consideration when administering high doses of vasopressor or inotropic drugs to TBI patients. VIS is easy to calculate and is an effective method for the prediction of mortality. We have concluded that it may be used in ICU patients treated for TBI.

\section{- REFERENCES}

1. Caballero EB, Cubero JS, Vilchez FG, Jimenez JD, Villa FP, Bonet LA, Prado JLA, Galle EL, Galan LDLF, Lorite NM, Julve MS, Arranz AV, Rodriguez JLL, Loidi VB, FigalDP, Garcia JM, Leiro MC: Letter to the Editor. Evaluation of the preoperative vasoactive-inotropic score as a predictor of postoperative outcomes in patients undergoing heart transplantation. International Journal of Cardiology 185: 192-194, 2015

2. Curry P, Viernes D, Sharma D: Perioperative management of traumatic brain injury. Int J CritllInInj Sci 1(1):27-35, 2011

3. Dewan MC, Rattani A, Gupta S, Baticulon RE, Hung YC, Punchak M, Agrawal A, Adeleye AO, Shrime MG, Rubiano AM, Rosenfeld JV, Park KB: Estimating the global incidence of traumatic brain injury. J Neurosurg 27:1-18, 2018

4. Favia I, Vitale V, Ricci Z: To the editor: The vasoactive-inotropic score and levosimendan: Time for LVIS? J Cardiothorac Vasc Anesth 27(2):e15-16, 2013

5. Gaies MG, Gurney JG, Yen AH, Napoli ML, Gajarski RJ, Ohye RG, Charpie JR, Hirsch JC: Vasoactive-inotropic score as a predictor of morbidity and mortality in infants after cardiopulmonary bypass. Pediatr Crit Care Med 11: 234-238, 2010

6. Gaies MG, Jeffries HE, Niebler RA, Pasquali SK, Donohue JE, Yu S, Gall C, Rice TB, Thiagarajan RR: Vasoactive-inotropic score is associated with outcome after infant cardiac surgery: An analysis from the pediatric cardiac critical care consortium and virtual PICU system registries. Pediatr Crit Care Med 15: 529-537, 2014

7. Garcia RU, Walters III HL, Delius RE, Aggarwal S: Vasoactive inotropic score (VIS) as biomarker of short-term outcomes in adolescents after cardiothoracic surgery. Pediatr Cardiol $37: 271-277,2016$

8. Haque A, Siddiqui NR, Munir O, Saleem S, Mian A: Association between vasoactive-inotropic score and mortality in pediatric septic shock. Indian Pediatr 52(4):311-313, 2015 
9. Hylands M, Toma A, Beaudoin N, Frenette AJ, D'Aragon F, Cote EB, Charbonney E, Moller MH, Laake JH, Vandvik PO, Siemieniuk RA, Rochwerg B, Lauzier F, Green RS, Ball I, Scales D, Murthy S, Kwong JSW, Guyatt G, Rizoli S, Asfar $\mathrm{P}$, Lamontagne F: Early vasopressor use following traumatic injury: A systematic review. BMJ Open 7:e 017559, 2017

10. Hylands $M$, Toma A, Beaudoin N, Frenette AJ, D'Aragon F, Cote EB, Hylander M, Lauzier F, Siemieniuk RA, Charbonney E, Kwong J, Laake JH, Guyatt G, Vandvik PO, Rochwerg B, Green R, Ball I, Scales D, Murthy S, Rizoli S, Asfar P, Lamontagne F: Vasopressor use following traumatic injury: Protocol for a systematic review. BMJ Open 7:e 014166, 2017

11. laccrino C, Carretta A, Nicolosi F, Morselli C: Epidemiology of severe traumatic brain injury. Journal of Neurosurgical Sciences 62(5): 535-541, 2018

12. Kinoshita K: Review. Traumatic brain injury: Pathophysiology for neurocritical care. J Intensive Care 4: 29, 2016

13. Kumar M, Sharma R, Sethi SK, Bazaz S, Sharma P, Bhan A, Kher V: Vasoactive Inotrope Score as a tool for clinical care in children post cardiac surgery. Indian Journal of Critical Care Medicine 18(10): 653-658, 2014

14. Mclntosh AM, Tong S, Deakyne SJ, Davidson JA, Scott HF: Validation of the vasoactive-inotropic score in pediatric sepsis. Pediatr Crit Care Med 18(8):750-757, 2017

15. Munter LD, Polinder S, Lansink KWW, Cnossen MC, Steyerberg EW, Jongh MAC: Mortality prediction models in the general trauma population: A systematic review. Injury Int J Care Injured 48: 221-229, 2017

16. Na SJ, Chung CR, Cho YH, Jeon K, Suh GY, Ahn JH, Carriere KC, Park TK, Lee GY, Lee JM, Song YB, Hahn JH, Choi JH, Choi SH, Gwon HC, Yang JH: Vasoactive inotropic score as a predictor of mortality in adult patients with cardiogenic shock: Medical therapy versus ECMO. Rev Esp Cardiol (Engl Ed) pii: S1885-5857(18)30007-0, 2018
17. Ozyurt E, Goksu E, Cengız M, Yılmaz M, Ramazanoglu A: Retrospective analysis of prognostic factors of severe traumatic brain injury in a university hospital in Turkey. Turk Neurosurg 25(6):877-882, 2015

18. Prys-Picard CO, Shah SK, Williams BD, Cardenas V, Sharma G: Outcomes of patients on multiple vasoactive drugs for shock. Journal of Intensive Care Medicine 28(4):237-240, 2012

19. Sookplung P, Siriussawakul A, Malakouti A, Sharma D, Wang J, Souter MJ, Chesnut RM, Vavilala MS: Vasopressor use and effect on blood pressure after severe adult traumatic brain injury. Neurocrit Care 15(1):46-54, 2011

20. Spaite DW, Hu C, Bobrow BJ, Chikani V, Barnhart B, Gaither JB, Denninghoff KR, Adelson PD, Keim SM, Viscusi C, Mullins T, Sherrill D: The impact of combined prehospital hypotension and hypoxia on mortality in major traumatic brain injury. Ann Emerg Med 69(1):62-72, 2017

21. Temgoua MN, Tochie JN, Agbor VN, Tianyi FL, Tankeu R, Danwang C: Simple mortality predictive models for improving critical care in resourcelimited settings: An insight on the modified early warning score and rapid emergency medical score. Int J Appl Basic Med Res 8(3):199-201, 2018

22. Yamazaki Y, Oba K, Matsui Y, Morimoto Y: Vasoactive-inotropic score as a predictor of morbidity and mortality in adults after cardiac surgery with cardiopulmonary bypass. Journal of Anesthesia 32:167-173, 2018 